\title{
Reviewing as social practice: Institutional constraints on critics' attention for contemporary fiction*
}

\author{
Susanne Janssen* \\ Erasmus University Rotterdam
}

\begin{abstract}
This article examines the activities of literary reviewers and the conditions under which they perform their task of judging recently published works of fiction. Reviewers and other members of the institution of criticism usually present their assessments as a highly personal matter, in which the intrinsic properties of the texts under consideration are focused on. To understand why this view is incorrect one must consider the choices and statements of reviewers in relation with the social environment in which they come about. Following a theoretical discussion of the institutional nature of critical choices and judgements, an empirical analysis is undertaken of the selection Dutch reviewers made from the supply of new fiction titles in the 1970s and 1990s. The findings show that reviewers tend to be on the safe side when dealing with recently published texts. In addition to the text itself, they take due note of extra-textual indicators of quality, such as the publishing house that marketed the title and, especially, the assessments of other critics. In doing so, they reduce the uncertainty as to which works deserve their attention, Hence, they reduce the risk of making the choices that might jeopardize their status as literary experts.
\end{abstract}

\section{Introduction}

Underlying the study presented here is the assumption that the institution of literary criticism plays a crucial role in the symbolic production of literature. The attention members of this institution pay to certain fiction texts is taken to be constitutive of their social recognition as literary works of a certain standard. The complementary activities of reviewers, essayists and academic critics determine to a great extent which texts in a given period are held to be legitimate forms of literary fiction, what rank they are supposed to occupy within the hierarchy of literary works, and what

\footnotetext{
* Special thanks go to Kees van Rees and two Poetics reviewers for their helpful comments on previous drafts and to Pieter Nieuwint for his editing.

*E-mail: s.janssen@eshcc.eur.nl
} 
statements count as proper and relevant ways of characterizing these texts. The choices and statements of journalistic critics represent a first phase in the constitution of the repertory of literary works and in their ranking according to quality.

In the past fifteen years pioneering research into the social foundations and effects of literary (art) criticism and into the activities of critics and other connoisseurs has been reported, notably in Poetics and Spiel (Bourdieu, 1980, 1983; Van Rees, 1983a,b, 1987, 1989; Becker, 1982: 131-164; Bevers, 1985; Van Dijk, 1994;

Janssen, 1988, 1991; Peterson, 1985; Rosengren, 1985, 1987; De Nooy, 1991; Schmidt, 1982, 1989; Verdaasdonk, 1983, 1987; Viehoff, 1989 and 1991). These empirically oriented studies provide a good basis on which to question the self-image which literary criticism propagates of its own activities. Critics and other connoisseurs function within a specific social framework, which to a great extent shapes their activities as well as their own image thereof.

This article scrutinizes the activities of literary reviewers and the conditions under which they perform their task of judging recently published works of fiction.

Reviewers' attention for authors and their works will be conceived of as part of an institutional practice. Members of literary institutions as well as non-professional readers usually perceive the involvement with literature, whether it concerns the reading, appreciation or discussion of texts, as a highly individual affair. This also holds for the way daily and weekly reviewers deal with the supply of new fiction titles. Their selection and valuation of texts is generally presented as a personal matter, in which the intrinsic properties of the texts under consideration are focused on.

Below, this view is put into perspective by considering the choices and statements of reviewers in connection with the social context in which they arise. Sections 2 and 3 provide an outline of the theory underlying the research. It is assumed that the activities of literary reviewers are regulated by the norms, ideas and practices that prevail within their institutional environment. Subsequently, an effort is made to sustain these views with empirical evidence regarding the selection made by Dutch reviewers from the new fiction book supply in the late 1970s and early 1990s.

\section{The institutional nature of critical choices and judgements}

The views critics and reviewers propagate of their own activities emphasize their autonomy and the decisive role of 'pure', 'internal (artistic)' criteria in their assessment of literary works. These self-assessments are seldom challenged by members of other literary institutions and non-professional readers. Yet, the arguments and findings of the above-mentioned advocates of an empirical, institutional approach to literature make it clear that they require radical change.

The key problem is that by this self-image critics both ignore a variety of social factors which are in fact determinants of critical activities and wrongly suggest that the collective actions of various categories of critics result in an objective assessment of the distinct value of literary works (Van Rees, 1983b). In the past few decades it has been adequately argued that there is no specific capacity or procedure enabling a critic to identify textual properties in an unequivocal way. Besides, there exists no 
logical or empirical connection between the (alleged) presence of certain properties in a text and a particular value judgement. The idea of such a relationship can only be based on normative grounds (cf. Weitz, 1966; Ellis, 1974: 72-103; Radford and Minogue, 1981: 88-114; Verdaasdonk, 1981; Van Rees, 1986: 53-77).

Neither the absence of a reliable instrument for grounding critical statements nor the coexistence of different conceptions of literature, prevent critics and reviewers from reaching agreement as to which fiction texts deserve their attention. Nor does it hinder their reaching consensus on the nature and value of any particular work. This consensus is often put forward by critics as evidence of their ability to assess literary quality in an intersubjective way. The outside world tends to consider this agreement among critics as proof of criticism's reliability in assessing the value of literary works; after all, when critics independently of one another prove to make the same assessments, these must be correct. This view is erroneous. The social fact of a consensus is mistaken for proof that the assessment is reliable and valid.

Following this line of argument, one should not overlook the fact that critics take due note of each other's achievements and are very considerate of the statements of their colleagues. It is precisely this mutual attention among agents in the literary field that is vital to the genesis of a generally accepted view on the nature and value of any work. From studies into the reception of certain texts or bodies of works it appears time and again that critics and reviewers fall back on previous statements by critics, as well as by the author in question, and incorporate these statements in their own reviews (Bel, 1993; Van Dijk, 1994; Janssen, 1994; Van Rees, 1987; Ritchie, 1988; Rodden, 1989). As a result the critical assessments of these works display a growing similarity as time goes on.

This phenomenon may be metaphorically described as a process of 'orchestration' (Bourdieu, 1983; Van Rees, 1987). Critics and other connoisseurs little by little attune their judgements to each other, without making explicit references to each other's work and without there being a single conductor who might be shown to be responsible for the harmony. There are no hard and fast rules involved in the process by which critics gradually reach agreement. Nevertheless, this process is highly coercive in nature. The larger the number of critics who agree on the nature and value of a work, the more critics are inclined to comply with this assessment. As appears from several casestudies into the reaching of consensus (Van Rees, 1987; Janssen, 1994), even reviewers who initially took almost opposite views, reverse their opinion of a work or cease to discuss it. Of course, this does not mean that no 'note of discord' is to be heard in the critiques of renowned work. In fact, it occurs quite often that a critic utilizes his review of work by an established author to distinguish himself from his colleagues.

To understand the propensity of critics to comply with the communis opinio as well as their craving for distinction, one has to consider the institutional framework in which critics are functioning. As Bourdieu (1983: 317 ) points out:

"Every critical) affirmation contains, on the one hand, a recognition of the value of the work which occasions it, which is thus designated as worthy object of legitimate discourse (...), and, on the other hand, an affirmation of its own legitimacy. Every critic declares not only his judgement of the work, but also his claim to the right to talk about it and judge it." 
So, in critical practice not only the status of literary products and their makers is at issue but also that of critics themselves. Every self-respecting critic will try to gain recognition as connoisseur and to inspire confidence in his ability to assess the properties and quality of a work. However, there is no objective agency or procedure that might prove his assessments true or false. Only the similarity or comparability of his statements with those made by other experts provides a clue to whether or not he is right. That is why critics take due note of the achievements of (reputed) colleagues. Their choices and statements are the sole touchstone of a critic's own choices and statements. Besides, by considering the achievements of other critics he may reduce the uncertainty as to which works deserve his attention and how to express this attention. The highest conceivable confirmation of any critic's assessments is their being accepted as true or important by colleagues and, subsequently, by members of literary institutions and non-professional readers. A critic's reputation as a literary expert is inseparably related to the extent to which, over a period of time, his judgements have met with his colleagues' approval (Van Rees, 1989).

This by no means implies that critics confine themselves to merely complying with other critical viewpoints, nor that they should do so. On the contrary, in order to enhance his prestige as a literary expert, a critic has to distinguish himself from his colleagues. Originality represents a positive value not only in the valuation of literary works, but also in the valuation of reviews and critiques. The appreciation of a critique strongly depends on whether it is perceived as an original, inventive viewpoint. So, a critic should try to develop perspectives on literary works which might be taken for a refinement or enrichment of previous critical tenets. By sometimes deviating in his value judgement or his choice of works for discussion a critic may show himself as an 'independent expertwith views of bis own'.

However, there are limits to the scope for dissent. Critics and reviewers function within a setting in which the highest form of recognition one may hope to achieve is the approval of one's peers. This fact curtails their freedom to advance new or deviant views regarding contemporary fiction. Roughly speaking, a critic's selection of works for discussion should be the same as the selection made by bis colleagues. A critic who repeatedly concerns himself with works not considered to be worthwhile by other critics may arouse doubts about his expertise. The same holds for a critic who omits to deal with works deemed important by his fellow experts. In repeatedly taking views that are perceived as incompatible with those held by the majority of reviewers, a critic risks bis reputation.

\section{Assumptions on reviewers' selection}

On the basis of the foregoing, reviewers may be expected to make fairly similar choices from the supply of new fiction titles and to be very considerate of previous critical choices and judgements. Their selection is likely to focus on titles by authors whose previous work has already received a good deal of reviewers' attention.

However, reviewers cannot be expected to turn their attention exclusively to new works by renowned authors, if only for the trivial reason that a considerable part of 
the review pages would remain blank. More importantly, they would fail to fulfil a major task of journalistic criticism, i.e. to report on the entire contemporary literary production (Van Rees, 1983b: 402ff.). With a view to his status as expert, the individual critic appears obliged to express his opinion on the work by new writers. Otherwise, he might gain a reputation for cowardice and certainly will never be thought of as the discoverer of an alleged masterpiece. However, the absence of clear and unequivocal criteria is especially made manifest in the case of beginning authors. Generally, there are no previous critical assessments a reviewer might somehow use as a peg for determining his own response. In this highly uncertain situation, the publishing house that marketed the work is likely to serve as a quality indicator on the strength of which reviewers decide whether or not to discuss it. By considering the publisher's name, reviewers reduce the, uncertainty as to which first book publications deserve their attention.

So, it is hypothesized that in selecting a work for a review, reviewers take into account several attributes that are external to the book in question, but are related to its institutional setting. Their decision whether or not to pay attention to a particular title presumably depends to a great extent on the critical attention for previous work by the author in question. In the case of a first book publication, the publishing house that marketed the work probably is a more or less decisive factor in whether or not it will be reviewed. ${ }^{1}$

Of course, other factors can also have an effect on the amount of attention a title receives from reviewers. For instance, most Dutch readers prefer works of prose to works of poetry. It may be assumed that dailies and weeklies aim at attuning the literary information they offer to the interests of their readership and therefore generally devote more space to reviews of prose than to reviews of poetry. Such factors might be called 'exogeneous' because they do not bear on a critic 's valuation of individual works, but on structural differences as regards the space which is available in dailies and weeklies for specific categories of titles.

\section{Method}

Underlying the analysis presented here is the assumption that the activities and opinions of reviewers are shaped by their institutional environment. In order to fulfil the function of reviewer they have to respect the unwritten rules of the institution of literary criticism. During the postwar period one of these rules states that literary works should be valued on the basis of 'pure', 'internal', 'literary' criteria. All other, socalled 'external' considerations are deemed inadmissible in the assessment of literary works.

\footnotetext{
${ }^{1}$ Of course, in the case of both debutant and non-debutant authors, other indicators may also be of significance in choosing a title fora review, notably the literary magazine(s) in which previous work by the author appeared; his performance as reviewer, essayist or editor and his membership of literary organizations. The significance of such additional literary activities of the author is elaborated upon in Janssen (forthcoming).
} 
In view of this it is hardly surprising that reviewers tend to stress both the autonomy of the reviewer and the decisive role of 'purely literary (artistic)' criteria in the process of deciding which texts to discuss. However, it is doubtful whether this institutionally determined self-image provides an adequate account of the empirical routine. Instead of exploring reviewers' own views of the selection process, this article analyses the results of this process, i.e. the choices made by Dutch reviewers from the supply of new fiction titles.

To gain insight into the selection made by reviewers, it does not suffice to collect data regarding titles they actually selected for a review. Titles that were not reviewed should be also taken into account. Only by comparing both categories of titles one is able to specify the factors affecting the selection process.

Furthermore, not only the current reviewing situation will be considered below, but also reviewers' selection at an earlier point in time. Many commentaries on the Dutch reviewing situation lament that nowadays, mainly as a result of commercial pressures, there is little left of the independent reviewer who is perfectly free to review only those works which he considers worthwhile. Although there is no doubt some truth in this, such commentaries wrongly suggest that until recently reviewers were more or less autonomous in their choice of works for a review. They overlook the above-mentioned institutional constraints on the modus operandi of reviewers, which are certainly not a new phenomenon. To sustain this view, the data collection was not confined to the Dutch reviewing situation in the nineties. Instead, data regarding two different years, 1991 and 1978, were collected. The choice of these two years is based on pragmatic reasons, viz. the availability of a computer file containing part of the required data.

\subsection{Data collection}

The gathering of the data comprised two steps. First, a database was built up embracing all fiction titles (narrative prose and poetry) originally written in Dutch and brought out for the first time in 1978 or 1991 by a Dutch or Flemish publishing house. Next, the database was supplemented by data regarding the attention each title received in the Dutch daily and weekly press.

The inventory of titles is based on Boekblad, the independent Dutch book-trade magazine. It is published every week and contains an extensive bibliography of newly published hooks in the Netherlands and Flanders. On the basis of their Nugi-codes, books for children and hooks written in dialect were removed from the data-base. As regards hooks published in 1978, the database comprises all titles with one of the following Nugi-codes: 410 (literary novels and short stories), 413 (poems), 420 (thrillers, detective novels, adventure stories and spy novels), 450 (historical novels, family sagas and novelettes), 460 (regional novels), 470 (realistic novels), 480 (war novels), 490 (humoristic and comic hooks), 499 (other works of fiction).

\footnotetext{
${ }^{2}$ Nugi refers to the Dutch Uniform Genre Classification. This is a coding system the Dutch book publishing fraternity uses to categorize their publications before sending them to the legal depot at the Royal Library in The Hague.
} 
As to the publications of 1991, all titles belonging to one of the following Nugicategories were filed: 300 (literary novels and short stories), 310 (literary poems), 311 (popular poems), 312 (religious poems), 331 (thrillers and adventure stories), 332 (detective novels), 333 (war novels), 335 (science fiction), 340 (regional novels and family sagas), 341 (historical novels), 342 (novelettes and folk novels), 350 (legends and folk tales), 380 (other works of fiction), 381 (collections of stories), 382 (social novels). For each title the following data were recorded:

- The name and year of birth of the author.

- The year the author made his or her debut in the domain of narrative prose and/or poetry.

- The genre and Nugi-code of the title.

- Whether the title had been classified as literature or as non-literary fiction, i.e. whether the title had been assigned Nugi-codes $410 / 300$ or one of the other codes for works of narrative prose.

Tuis variable only applies to works of prose, since in 1978 the Nugi-system did not make a distinction between literary poems and other works of poetry.

- The geographical origin of the title.

A distinction was made between Dutch and Flemish publications, that is to say titles brought out by Dutch and Flemish publishing houses.

- The name and type of publishing house that marketed the title.

According to the extent of their title production in 1978 and 1991, all publishing firms were classified as either large (over 20/25 titles per year), medium-sized (620/25 titles per year), or small (less than 6 titles per year). Subsequently, using the Nugi-system, a distinction was drawn between non-literary and literary publishing firms. Among the latter were rated those publishers whose publications in the field of narrative prose consisted for the greater part of titles with Nugi-codes 410 or 300 . In the case of small publishing firms, the application of this criterion proved to be problematic, because a substantial number of these firms published mainly hooks of poetry. Therefore, within the category of small publishing houses no further distinction was made.

- Whether the title happened to be the author's first book publication in the domain of poetry or narrative prose. That is to say, a first novel by an author who had previously published works of poetry or drama was also included as a first book publication.

Once the record of titles was completed, data bearing on the reviews each of these titles received in the Dutch daily and weekly press were recorded. For each review the following data were filed:

- The names of the reviewer and the review medium.

- The kind of medium (national daily newspaper, regional daily or weekly magazine) in which the review appeared.

- The date the review was published and the number of words per review.

- Finally, it was recorded whether or not the reviewer also discussed one or more titles by other authors. 
The record of reviews is based on the collections available in the NLMD (Dutch Literary Museum) and the NBLC (Dutch Library and Reading Centre). Not Dutch dailies and weeklies are represented in these collections. However, the list of media for which the reviews were systematically collected by these two institutions is sufficient to form a reliable picture of critical selection. As to 1978, the file contains data with respect to 34 media: 6 weekly magazines, 8 national and 20 regional daily newspapers. For 1991, data regarding the reviews in 29 media were registered: 5 weeklies, 7 national and 17 regional dailies. ${ }^{3}$

\section{Critics' attention for new works of fiction}

This section reports on three analyses of the recorded data. The analysis in section 5.1 is aimed at describing reviewers' attention ${ }^{4}$ for the supply of new titles in 1978 and 1991. It takes into account the distribution of the reviews over the book supply and the attention given to various categories of titles, differentiating on the basis of the variables 'geographical origin', 'genre', 'type of publishing house', 'author's age' and 'first book publication vs. other new title'. In section 5.2 structural differences in attention between media and reviewers are examined. The purpose of the analysis in section 5.3 is to explain the strong variation in reviewers' attention for individual titles.

\subsection{Attention for the supply of new titles in 1978 and 1991}

Table 1 gives a survey of critical attention for the supply of new titles. By the phrase 'title selected for a review' is meant that at least one review was devoted to this title in the Dutch daily and weekly press. On average titles that appeared in 1978 received more than three reviews and those published in 1991 about two reviews. These figures, of course, prove little or nothing about the distribution of the reviews.

Table 1

Reviewers' attention for the supply of new fiction titles

\begin{tabular}{lll}
\hline & & 1991 \\
\hline Total number of reviews & 1978 & 1211 \\
Total number of titles & 1494 & 657 \\
Percentage of titles selected for a review & 444 & $36 \%$ \\
Average number of reviews per title & $54 \%$ & 1.8 \\
Average number of reviews per title selected for a review & 3.4 & 5.1 \\
Average length (words) of the reviews per title selected for a review & 6.2 & 391 \\
\hline
\end{tabular}

\footnotetext{
${ }^{3}$ This means that for both years the collection of reviews is fairly complete as regards the national daily and weekly press. As to the regional press, data regarding one third of the existing newspapers were recorded (cf. Van Alsem et al., 1982; Herpers et al., 1993: 150).

${ }^{4}$ In the following pages, 'attention' must be understood to mean 'reviewers' attention'.
} 
Fig. 1 shows for both years the distribution of the reviews, which appears to be extremely skewed. The number of reviews per title ranges from zero to 24 and 22 reviews in 1978 and 1991, respectively. About half of the fiction titles published in 1978 and about two-thirds of the titles marketed in 1991 received no attention at all in the Dutch press. In 1978, 21 titles (5\%) account for a quarter of the reviews, whereas $40 \%$ of the reviews were devoted to $10 \%$ of the titles. In 1991 , the distribution is even more skewed as $10 \%$ of the book titles account for more than $60 \%$ of the reviews.

\section{Reviews(\%)}

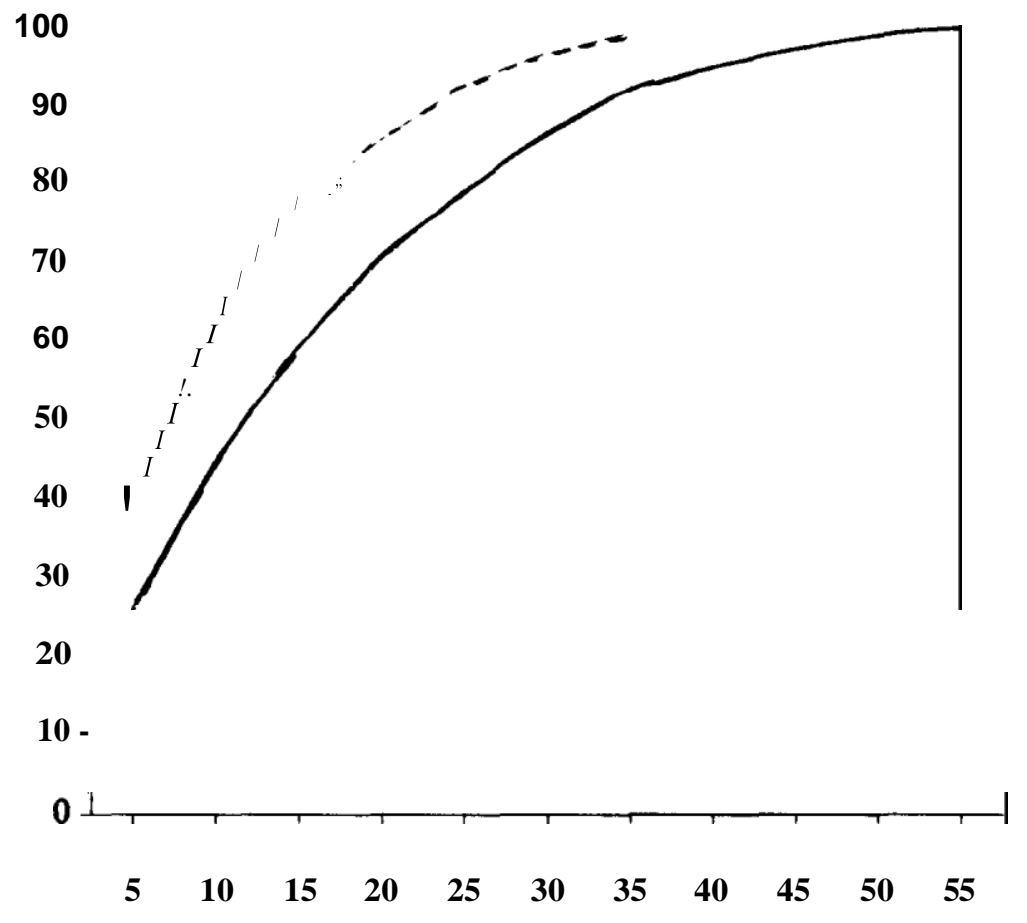

Fig. 1. The distribution of the reviews.

Titles $(\%)$

The upper part of Table 2 shows for both years that the publications of Dutch publishing houses were given more attention than those brought on the market by Flemish firms. A high proportion of the latter category of titles received no attention at all on the part of reviewers. Moreover, when we consider only titles that were selected fora review, both the average number of reviews per title and the average length of these reviews appear to be considerably smaller in the case of titles from Flanders.

The lower part of Table 2 gives an overview of the critical reception of new works of poetry and prose. Books of poetry received less attention in the Dutch press. Although in 1978 the two categories do not vary in percentage of titles selected for a review, there appears to be a considerable difference in the average number of reviews per title. Books of prose received about twice as many reviews. 
Table 2

Reviewers' attention according to geographical origin and genre

\begin{tabular}{lcllllllll}
\hline & 1978 & \multicolumn{7}{c}{1991} \\
& \cline { 2 - 9 } & \multicolumn{1}{c}{ Titles } & & \multicolumn{2}{c}{ Reviews per title } & \multicolumn{2}{c}{ Titles } & \multicolumn{2}{c}{ Reviews per title } \\
\cline { 2 - 9 } & $N$ & Reviewed & Number & Length & $N$ & Reviewed & Number & Length \\
\hline Dutch & 388 & $56 \%$ & $3.7(6.5)$ & 483 & 538 & $40 \%$ & $2.2(5.4)$ & 398 \\
Flemish & 56 & $41 \%$ & $1.2(3.0)$ & 393 & 119 & $18 \%$ & $0.3(1.7)$ & 314 \\
Poetry & 175 & $53 \%$ & $2.2(4.1)$ & 406 & 220 & $26 \%$ & $0.8(2.9)$ & 361 \\
Prose & 269 & $55 \%$ & $4.1(7.5)$ & 517 & 437 & $41 \%$ & $2.4(5.8)$ & 400 \\
Literary & 133 & $84 \%$ & $7.5(8.9)$ & 567 & 255 & $60 \%$ & $3.8(6.3)$ & 413 \\
Non-literary & 136 & $27 \%$ & $0.9(3.3)$ & 363 & 182 & $15 \%$ & $0.4(2.6)$ & 328 \\
\hline
\end{tabular}

Note: $\mathrm{N}=$ number of new titles; Reviewed=percentage of titles selected fora review; Number=average number of reviews per title (in parentheses the average number of reviews per title selected for a review); Length=average length (words) of the reviews per title selected for a review. Table I provides the overall figures.

Furthermore, the mean length of these reviews is substantially greater than the mean length of the reviews of poetry. In 1991, almost three quarters of the new titles of poetry received no attention at all in the Dutch press, as against about $60 \%$ of the titles of prose. Taking into account only titles of poetry that were selected for a review, both the number and size of reviews of these titles appear to be small as compared to reviewers' attention for works of prose.

The differences in attention between poetry and prose are mainly the result of the high scores of the (sub)category of literary prose. In both years the lion's share of the non-literary works of prose received no attention at all from reviewers. With respect to the book supply of 1991 the Nugi-system also makes a distinction between literary and non-literary poetry, which allows further comparison. It appears that literary poetry as well as literary prose did receive more attention than non-literary titles (of both prose and poetry). However, within both the categories 'literary' and 'non-literary', hooks of prose have higher scores than hooks of poetry.

As mentioned before, the heading 'non-literary prose' refers to titles from a number of Nugi-categories. These categories vary considerably in amount of reviewers' attention. Both in 1978"and 1991 detective novels, thrillers and adventure stories received more attention than other non-literary genres.

Table 3 gives an overview of the amount of attention that was paid to the publications by the five categories of publishing firms distinguished before. Roughly, the figures show a division between categories $\mathrm{A}$ and $\mathrm{B}$, on the one side, and categories $\mathrm{C}, \mathrm{D}$ and $\mathrm{E}$, on the other. The majority of the titles brought out by large and mediumsized literary publishers in 1978, as well as a fairly high percentage of their publications in 1991, appear to be reviewed in the Dutch press. On the other hand, the majority of titles marketed by non-literary and small publishers received no attention on the part of reviewers. 
Table 3

Reviewers' attention according to type of publishing house

\begin{tabular}{|c|c|c|c|c|c|c|c|c|}
\hline \multirow[t]{3}{*}{ Publisher } & \multicolumn{4}{|l|}{1978} & \multicolumn{4}{|l|}{1991} \\
\hline & Titles & \multicolumn{3}{|c|}{ Reviews per title } & \multirow{2}{*}{$\begin{array}{c}\text { Titles } \\
N\end{array}$} & \multicolumn{3}{|c|}{ Reviews per title } \\
\hline & $N$ & Reviewed & Number & Length & & Reviewed & Number & Length \\
\hline A. Lit./Large & 115 & $91 \%$ & $8.1(8.9)$ & 543 & 163 & $74 \%$ & $4.6(6.2)$ & 412 \\
\hline B. Lit./Medium & 69 & $86 \%$ & $5.1(6.0)$ & 502 & 133 & $47 \%$ & $2.4(5.0)$ & 408 \\
\hline C. Non-lit./Large & 39 & $31 \%$ & $1.0(3.3)$ & 399 & 77 & $10 \%$ & $0.2(1.8)$ & 362 \\
\hline D. Non-lit/Med. & 113 & $25 \%$ & $0.6(2.6)$ & 353 & 100 & $6 \%$ & $0.2(2.5)$ & 336 \\
\hline E. Small & 108 & $34 \%$ & $0.9(2.7)$ & 351 & 184 & $22 \%$ & $0.7(3.0)$ & 316 \\
\hline
\end{tabular}

Note: $\mathrm{N}=$ number of new titles; Reviewed=percentage of titles selected fora review; Number=average number of reviews per title (in parentheses the average number of reviews per title selected for a review); Length=average length (words) of the reviews per title selected fora review. Table I provides the overall figures.

When we consider the mean number of reviews of titles selected for a review and the average length of these reviews, we find the same division between the five categories of publishing firms. Titles from categories C, D and E received less and shorter reviews than those belonging to categories A and B. In their turn, hooks by the latter category of literary publishers were not reviewed as frequently and extensively as the publications of large literary firms. In 1991, category B in addition contains a comparatively large amount of titles that were not reviewed at all.

Table 4

Reviewers' attention according to author's year of birth

\begin{tabular}{|c|c|c|c|c|c|c|c|c|}
\hline \multirow[t]{3}{*}{ Year of birth } & \multicolumn{4}{|c|}{1978} & \multicolumn{4}{|c|}{1991} \\
\hline & \multicolumn{2}{|c|}{ Titles } & \multicolumn{2}{|c|}{ Reviews per title } & \multicolumn{2}{|c|}{ Titles } & \multicolumn{2}{|c|}{ Reviews per title } \\
\hline & $N$ & Reviewed & Number & Length & $N$ & Reviewed & Number & Length \\
\hline Before 1905 & 46 & $47 \%$ & $3.0(6.5)$ & 510 & 9 & $22 \%$ & $0.3(1.5)$ & 388 \\
\hline $1905-1924$ & 107 & $55 \%$ & $3.3(5.9)$ & 535 & 89 & $33 \%$ & $1.4(4.1)$ & 411 \\
\hline $1925-1944$ & 149 & $67 \%$ & $4.6(6.8)$ & 466 & 202 & $40 \%$ & $2.1(5.2)$ & 407 \\
\hline After 1944 & 59 & $72 \%$ & $4.2(5.7)$ & 409 & 194 & $60 \%$ & $3.2(5.4)$ & 366 \\
\hline
\end{tabular}

Note: The figures in the table do not include titles for which the author's year of birth was not recorded, or titles written by several co-authors. For 1978 this means 59 and 24 titles, respectively. For 1991, 101 and 62 , respectively.

On the basis of the year of birth of the author, titles have been divided into four categories. Table 4 gives an overview of the amount of attention given to each 'generation'. 
For both 1978 and 1991, the percentage of titles selected for a review is the highest for the youngest generation(s) of authors. On the other hand, reviews of titles by these authors on average appear to be substantially shorter than those of hooks by older writers. The mean number of reviews devoted to titles selected for a review shows little or no variation.

Table 5

Reviewers' attention for first book publications and other new titles

\begin{tabular}{lrlllllll}
\hline & 1978 & & \multicolumn{3}{c}{1991} \\
& Titles & & Reviews per title & Titles & Reviews per title \\
\hline & $N$ & Reviewed & Number & Length & $N$ & Reviewed & Number & Length \\
\hline $\begin{array}{l}\text { First book } \\
\text { publications }\end{array}$ & 95 & $49 \%$ & $2.9(5.9)$ & 413 & 126 & $42 \%$ & $1.7(4.0)$ & 360 \\
$\begin{array}{l}\text { Regular titles } \\
\text { Special editions }\end{array}$ & 269 & $59 \%$ & $3.7(6.3)$ & 489 & 444 & $39 \%$ & $2.2(5.5)$ & 402 \\
\hline
\end{tabular}

Note: $\mathrm{N}=$ number of new titles; Reviewed=percentage of titles selected for a review; Number=average number of reviews per title (in parentheses the average number of reviews per title selected for a review); Length=average length (words) of the reviews per title selected for a review. Table 1 provides the overall figures.

Finally, the question was addressed whether first book publications differ in critical attention from other new titles. With respect to the latter category, a distinction was made between 'regular' new titles and 'special' editions, such as anthologies, omnibuses, collected works and joint publications of several writers. As can be seen from Table 5, the special editions of both years were seldom reviewed.

Comparing reviewers' attention for regular new titles and works by debutants, we found that in 1978 a high percentage of the latter category appears to be unnoticed in the Dutch press. For first book publications the mean number of reviews per title and the average length of these reviews prove to be considerably smaller. In 1991, the two categories hardly vary in percentage of titles that received attention. How- ever, on average first book publications received fewer and shorter reviews.

\subsubsection{Discussion}

The figures in this section indicate that the scope of the selection made by the critical community - i.e. the number of different titles receiving attention from reviewers - is independent of the new book supply. Although in 1991 the supply of fiction titles increased by more than 5\% compared to 1978, the absolute number of titles reviewed proved to be almost the same for both years. The distribution of critical attention over the supply of new titles was found to be extremely skewed. In both years reviewers focused on a limited number of works, while the majority of new titles received little or no attention.

Moreover, reviewers' interest in specific categories of titles appeared to vary considerably. In 1978 as well as in 1991, hooks from Flanders, non-literary fiction, 
collections of poems, publications by non-literary and/or smaller publishing houses, books by older writers and first book publications received comparatively little attention. This holds for the proportion of titles that received attention on the part of reviewers, the mean number of reviews per title selected for a review and/or the length of these reviews.

When we compare the attention for the book supply of 1991 and 1978, a number of observations can be made. Firstly, in 1991, the distribution of critical attention appears to be even more skewed than in 1978. The percentage of titles that was selected fora review bas decreased by $18 \%$ compared to 1978 . In 1978 , over half of the newly published titles was reviewed at least once in the daily and weekly press. In 1991 this applies to only one third of the book supply. The decline in the per-centage of titles reviewed occurred with respect to each separate category of books in this section. However, closer inspection of the respective tables shows that categories which were rather 'unpopular' to begin with, suffered most from the decline. Furthermore. the titles that got through the critical selection in 1991 were discussed neither as frequently nor as extensively as those published in 1978. Finally, there proves to be a remarkable decrease in critical attention for poetry. In 1978 over a quarter of the reviews of new Dutch fiction dealt with books of poetry, whereas in 1991 this percentage amounts to less than 15. Research by Willems and Prins (1977) indicates that we are facing a development that probably started somewhere in the 1970s. As can be seen from their data, in 1968 around $35 \%$ of the reviews of fiction in national daily newspapers was still devoted to works of poetry.

\subsection{Structural differences between media and reviewers}

The concentration of critical attention on a small proportion of the new fiction supply implies that to a great extent similar choices are made when it comes to selecting a title for a review. However, review media may show significant differences in their selection, for instance in the attention that is paid to particular genres. Such differences between periodicals may be caused by various factors, an important one presumably being the diverging interests of their respective readerships. The need for information about the supply of new books constitutes a prior condition for editorships of dailies and weeklies to allot space to book reviews. It may be assumed that up to a point (review) editors and reviewers aim at attuning the literary information they offer to the (alleged) interests of their readers. The Dutch reading public as a whole may be said to prefer works of narrative prose to works of poetry. The observation that books of poetry received less attention in the Dutch press than books of narrative prose probably should be viewed in this light.

However, dailies and weeklies cater for (partly) distinct groups of readers. Many regional newspapers serve a readership with a relatively low level of (cultural) edu-cation. The same holds for the so-called 'popular' newspapers among the dailies with a nationwide circulation, notably De Telefgraaf and Algemeen Dagblad. ${ }^{5}$

\footnotetext{
.${ }^{1}$ Cf. National Onderzoek Persmedia (1982) and Nipo Media Onderzoek (1992).
} 
In view of their level of (cultural) education the readers of these periodicals are generally taken to be less interested in literature - let alone in a 'difficult' genre such as poetry - than the (culturally) higher educated readers of (other) national dailies and news magazines. On the other hand they are assumed to have a relatively strong preference for non-literary fiction. ${ }^{6}$

The foregoing leads to the hypothesis that the various types of review media differ as regards both the size and the composition of the repertory of new titles to which atten-tion is paid. Most regional newspapers as well as the 'popular' national dailies publish less reviews than (other) national dailies and weeklies. In comparison with the latter types of media, they also allot little space to reviews of poetry, while paying much attention to non-literary prose. In section 5.2.1 these hypotheses will be examined. It is less straightforward to compare reviewers as regards their selection. This has to do with the fact that they strongly vary in the frequency of their publications and in their attention for particular genres. Obviously, reviewers may differ in their choice of titles fora review. In fact 'deviant' choices are made rather frequently, as appears from the substantial number of titles that is reviewed only once or twice. ${ }^{7}$ However, this variation does not seem to be a matter of deliberate idiosyncrasy.

Most reviewers belong to the category of reviewers discussing only a few titles per year. It is probably they who discuss most of the titles belonging to the category of titles receiving only one or two reviews. In comparison with this first category of reviewers, members of a second category are less likely to make 'deviant' choices. In view of their position as regular reviewers they discuss, and almost seem obliged to discuss, titles that are deemed important within the critical community and (hence) are also reviewed by other critics. Besides, being a regular reviewer enables them to choose the 'best bits' for a review. In section 5.2.2 this hypothesis will be tested.

\subsubsection{Structural differences between review media}

With regard to the new fiction book supply of the years 1978 and 1991 record was made of 1494 and 1211 reviews published by 34 and 29 periodicals, respectively. Table 6 presents the review production according to type of periodical.

In 1978 as well as in 1991 reviews in the regional press prove to be significantly shorter than the ones that appeared in media with a nationwide circulation. Reviews in weeklies in their turn comprise a considerably larger number of words than reviews in national daily newspapers.

Furthermore, in both years regional newspapers on average published considerably less reviews than national dailies. In 1978, the mean score of regional newspapers also lags far behind that of the weekly press. For 1991 the picture is quite different. In comparison with both national and regional dailies, the weekly magazines appear to have published a small number of reviews regarding the new fiction supply.

\footnotetext{
${ }^{6}$ Besides, subscribers toa regional newspaper presumably have a relatively strong interest in (cultural) information related to their own region or place of residence.

${ }^{7}$ Cf. Fig. 1.
} 
Table 6

Production of reviews according to type of periodical

\begin{tabular}{lccrr}
\hline & Weeklies & National dailies & Regional dailies & Total \\
\hline 1978 & & & & 34 \\
Number of periodicals & 6 & 8 & 20 & 1494 \\
Total number of reviews & 300 & 398 & 796 & 44 \\
Mean number of reviews & 50 & 50 & 40 & 574 \\
Mean length (words) of reviews & 721 & 598 & 507 & 29 \\
1991 & & & 17 & 1211 \\
Number of periodicals & 5 & 7 & 673 & 42 \\
Total number of reviews & 143 & 395 & 40 & 423 \\
Mean number of reviews & 29 & 56 & 375 & \\
Mean length (words) of reviews & 519 & 469 & & \\
\hline
\end{tabular}

When we consider the review production by the two 'popular' daily newspapers, the number of reviews that appeared in De Telegraaf proves to be substantially smaller than the mean score of the national dailies for both years. In 1991, also Algemeen Dagblad lags far behind the average number of reviews. Against expectations the latter newspaper appears to have paid attention to a comparatively large number of the new fiction titles that carne out in 1978. However, on the whole these reviews were much shorter than those published by other national dailies and relatively frequently considered several titles at the same time.

Next, it was examined whether the various types of periodicals differ in the amount of attention paid to works of poetry and to non-literary fiction.

The left part of Table 7 shows for each type of periodical the percentage of reviews devoted to poetry and prose. In 1978, about a quarter of the reviews within each segment of the press dealt with new books of poetry, whereas the majority of critical attention was devoted to works of prose. For the year 1991 chi square indicates a significant deviation from independence in the table. Although in 1991 only a small number of the reviews within each segment of the press concerned books of poetry, the regional media paid less attention to this genre than the periodicals with a nationwide circulation.

The right part of Table 7 shows for each type of periodical the distribution of reviews over literary and non-literary prose. Regarding the data on 1978 chi square is statistically significant. The regional media paid more attention to non-literary prose than both weeklies and national dailies. In 1991 there are no significant deviations from independence in the table.

Taking into account the genre distribution of the reviews in De Telegraaf and Algemeen Dagblad, it appears that in 1978 both 'popular' newspapers distinguish themselves from other national dailies by paying little attention to works of poetry; 16 and $12 \%$ of the reviews in these papers respectively, concerned books of poetry, against an overall percentage of 25\%. Moreover, in De Telegraaf $20 \%$ of the reviews was devoted to non-literary prose, whereas the percentage for the other national dailies ranges from $\mathrm{O}$ to $7 \%$. In 1991, neither of the two popular newspapers was found to be giving less attention to poetry than other national dailies. Both De Telegraaf and 
Table 7

Reviews (\%) devoted to poetry/prose and to literary/non-literary prose according to type of periodical

\begin{tabular}{|c|c|c|c|c|c|c|}
\hline & Poetry & Prose & $N$ & Literary prose & Non-literary prose & $N$ \\
\hline & \multicolumn{3}{|l|}{$1978 a$} & \multicolumn{3}{|l|}{$1978 b$} \\
\hline Weeklies & $25 \%$ & $75 \%$ & 398 & $93 \%$ & $7 \%$ & 226 \\
\hline National dailies & $25 \%$ & $75 \%$ & 300 & $92 \%$ & $8 \%$ & 300 \\
\hline Regional dailies & $27 \%$ & $73 \%$ & 796 & $87 \%$ & $13 \%$ & 584 \\
\hline \multirow[t]{3}{*}{ Total } & $26 \%$ & $74 \%$ & 1494 & $89 \%$ & $11 \%$ & 1110 \\
\hline & \multicolumn{3}{|c|}{ Chi-square $=0.772$} & \multicolumn{3}{|c|}{ Chi-square $=8.676^{*}$} \\
\hline & \multicolumn{3}{|l|}{$1991 a$} & \multicolumn{3}{|l|}{$1991 b$} \\
\hline Weeklies & $15 \%$ & $85 \%$ & 143 & $97 \%$ & $3 \%$ & 121 \\
\hline National dialies & $18 \%$ & $82 \%$ & 395 & $91 \%$ & $9 \%$ & 326 \\
\hline Regional dailies & $12 \%$ & $88 \%$ & 673 & $94 \%$ & $6 \%$ & 594 \\
\hline \multirow[t]{2}{*}{ Total } & $14 \%$ & $86 \%$ & 1211 & $93 \%$ & $7 \%$ & 1041 \\
\hline & \multicolumn{3}{|c|}{ Chi-square $=7.016^{*}$} & \multicolumn{3}{|c|}{ Chi-square $=4.162$} \\
\hline
\end{tabular}

Note: $* p<0.05$

Algemeen Dagblad devoted much attention to books of non-literary prose, namely $11 \%$ and $21 \%$ of their review production as opposed to an overall percentage of 7 .

\subsubsection{Structural differences between reviewers}

A substantial part of the reviews regarding the new fiction book supply of 1978 and 1991 proved to be unsigned. These reviews are left out of consideration in this section. The remaining 1257 and 1148 reviews were published by 174 and 200 reviewers, respectively. As mentioned before, the frequency of their publications differs widely. The number of publications per reviewer ranges from 1 to 107 in 1978 and from 1 to 78 in 1991. In bath years about $20 \%$ of the reviewers appears to be responsible for approximately $70 \%$ of the reviews.

As was argued before, the variance in title selection by reviewers does not seem due to idiosyncratic choice behavior. It has to do, among other things, with the frequency of a critic's publications. Compared to occasional reviewers, the regular reviewers are expected to make few 'deviant' choices. To test this hypothesis bath reviewers and titles were classified according to the number of reviews they published or received. Table 8 gives the distribution of the publications by regular and occasional reviewers over three categories of titles: titles that received considerable, moderate and little critical attention.

For bath years the chi-square indicates that the two groups of reviewers differ significantly from each other regarding the distribution of their publications over the three categories of titles. In 1978 as well as in 1991 the regular reviewers distinguished themselves from the occasional reviewers by paying comparatively much attention to titles from category A and by giving relatively little attention to those of category $\mathrm{C}$. These findings corroborate the hypothesis that the extent to which 
Table 8

Reviews $(\%)$ devoted by regular and occasional reviewers to titles that received considerable, moderate and little attention

Title category

$\begin{array}{llll}\text { A } & \text { B } & \text { C } & \text { N } \\ \text { Considerable attention } & \text { Moderate attention } & \text { Little attention }\end{array}$

\section{8}

Regular reviewers

$62 \%$

$31 \%$

$7 \%$

Occasional reviewers

$55 \%$

$32 \%$

$13 \%$

Total

$60 \%$

$31 \%$

1257

Chi-square $=11.622 *$

1991

Regular reviewers

$55 \%$

$41 \%$

$32 \%$

Occasional reviewers

$51 \%$

$37 \%$

Total

$33 \%$

Chi-square $=26.215 * *$

Note: Regular reviewers $=10$ or more reviews; Occasional reviewers $=1-9$ reviews. Title category: $\mathrm{A}=$ more than 8 reviews; $\mathrm{B}=4-8$ reviews; $\mathrm{C}=1-3$ reviews.

$* \mathrm{p}<0.01 * * \mathrm{p}<0.001$

reviewers make 'deviant' choices from the title supply is related to the question whether or not they publish their reviews on a regular basis.

\section{3. 'External' attributes affecting reviewers' attention for individual titles}

In sections 2 and 3 we argued that in selecting a work for a review, reviewers are likely to take into account several attributes that are external to the book in question, but are related to its institutional setting. Their decision whether or not to pay attention to a particular title presumably depends to a great extent on the critical attention for previous work by the author in question and on the publishing house that marketed the title. In the case of a first book publication, the publishing house probably is a more or less decisive factor in whether or not the title will be reviewed. From section 5.1 it appeared that the amount of attention for new fiction titles is connected with a number of other attributes that are also, for the most part, external to the hooks in question: the generation to which the author of the title belongs, the genre of the publication and its geographical origin. In comparison with the critical attention for an author's previous work and the publishing house marketing the title, the latter attributes probably have a small effect on a reviewer's decision whether or not to review a particular title. They do not bear on the valuation of individual titles, but relate to structural differences as regards the space which is available in the Dutch press for reviews of Dutch or foreign hooks, narrative prose or poetry, works by contemporary or older writers. In addition, the critical reception of an author's previous work is expected to be of greater importance to a critic's decision whether or not to review a title than the publishing house marketing the title. 
In section 5.3.1 these hypotheses are put to the test. Using multiple regression analysis we examine to what extent each of the attributes mentioned above account for the variation in critical attention for new fiction titles. First book publications will be excluded from this analysis.

In deciding whether or not to discuss work by a debutant, reviewers cannot take into account the interest previously shown by their colleagues. In this case the decision whether or not to review a particular title presumably (more) strongly depends on the publishing house launching the debut. This hypothesis is tested in section 5.3.2.

The analyses of differences in reviewers' attention for new fiction titles were only performed for 1978. This has to do with the availability of a file containing the required data on reviewers' attention for previous works by the authors involved. However, given the findings reported in sections 5.1 and 5.2, similar analyses of data on 1991 are not likely to yield divergent results.

\subsubsection{Analysis of reviewers' attention for titles by non-debutants}

The demarcation of the corpus of analysis and the data on attention for an author's previous work were accomplished as follows. In 1978, 444 new fiction titles appeared, of which 80 are special editions and 95 are first book publications; the latter are left out of account. For each of the remaining 269 titles the year in which the author published his previous work was looked up, i.e. the last book publication belonging to the same genre. ${ }^{8}$

Next, it was checked if the variable 'publication rhythm' - that is, the time interval between the publication of the author's new and previous title - should be added to the set of independent variables. For this purpose four groups of titles were distinguished on the basis of the number of years that had passed since the appearance of the author's previous book publication. An analysis of variance showed that groups did not significantly vary in amount of attention received. Hence, the variable 'publication rhythm' was not included in the analyses presented below.

Finally, the number of reviews devoted to the authors' previous works was recorded, except for those authors whose previous title appeared more than 7 years ago. ${ }^{9}$ As a result of this restriction the corpus of analysis comprises 230 titles.

Multiple regression analysis was applied to examine the influence of the abovementioned variables upon the amount of reviewers' attention (number of reviews) for new fiction titles. The set of independent variables consists of the quantitative variable reviewers' attention for previous work (i.e. the number of reviews devoted to the author's previous title) and five categorical variables: genre (prose vs. poetry), geographical origin (Dutch vs. Flemish), author's generation (born in/after 1925 vs. born before 1925), status of publishing house (literary vs. non-literary) and size of

8 This has been done using Brinkman's Cumu/ative Catalogue of Books, Baers' Lectuur-Repertorium and Zuiderent et al. (1980-).

${ }^{9}$ These data have been collected using the KUB-review database and the archives of the Dutch Literary Museum. 
publishing house (large vs. medium-sized/small). ${ }^{10}$ Dummy coding was used to represent the five categorical variables. ${ }^{11}$

Genre is coded 1 for prose; 0 for poetry. Geographical origin is coded 1 for Dutch; 0 for Flemish. Author's generation is coded 1 for authors born in 1925 or later; 0 for authors born before 1925. Status of publishing house is coded 1 for literary; 0 for nonliterary. Size of publishing house is coded 1 for large; 0 for medium sized or small.

To begin with, it was tested whether there are significant interaction effects between the independent variables. Since this proved not to be the case, the analysis was continued testing for main effects only. Table 9 gives the results of the regression analysis.

Table 9

Multiple regression analysis of the number of reviews devoted to new fiction titles with six and three predictors, respectively

\begin{tabular}{|c|c|c|c|c|}
\hline \multirow[t]{2}{*}{ Variable } & \multicolumn{2}{|l|}{ Equation 1} & \multicolumn{2}{|l|}{ Equation 2} \\
\hline & Beta & t-ratio & Beta & t-ratio \\
\hline Reviewers' attention for previous work & 0.595 & $13.116 * *$ & 0.611 & $13.834 * *$ \\
\hline Status of publishing house & 0.231 & $4.995 * *$ & 0.237 & $5.194 * *$ \\
\hline Size of publishing house & 0.132 & $3.242 *$ & 0.146 & $3.676^{* *}$ \\
\hline Genre & 0.051 & 1.363 & & \\
\hline Geographical origin & 0.038 & 1.020 & & \\
\hline \multirow[t]{2}{*}{ Generation } & 0.067 & 1.784 & & \\
\hline & $R^{2}=0.72 * *$ & & $R^{2}=0.71 * *$ & \\
\hline
\end{tabular}

Note: $N=230 ; \mathrm{R}^{2}=$ proportion of explained variance; Beta=standardized regression coefficient. $* \mathrm{p}<0.01 ; * \mathrm{p}<<0.001$

The left part of Table 9 shows that, all together, the six independent variables account for more than $70 \%$ of the variance in the amount of reviewers' attention for new fiction titles. However, from the significance of the resulting $R^{2}$ it does not follow that each variable makes a significant contribution to the explanation of the variation in reviewers' attention. 'Genre', 'geographical origin' and 'generation' do not have a significant effect on the number of reviews devoted to new fiction titles. ${ }^{12}$ Each of the other variables, 'reviewers' attention for previous work', 'status of publishing house' and 'size of publishing house', proves to make a significant contribution to the explained variance.

\footnotetext{
${ }^{10}$ So, instead of one variable (type of publishing house) based on both the size of a firm and the status of its predominant output (literary vs. non-literary), size and status are considered as separate variables in order to gain a better insight into their relative importance.

${ }^{11}$ This method of coding categorial variables is explained in Pedhazur (1982: 274ff.).

${ }^{12}$ An $F$-test allows to assess whether, after deduction of the proportion of variance accounted for by the other five variables, the covariance of the variable added last and the dependent variable is significant.

F-tests on the increments to $R^{2}$ show that 'genre', 'geographical origin' and 'generation' do not yield a significant increment to $R^{2}$ if they are added last in the equation.
} 
The right part of Table 9 shows that these three variables alone account for $71 \%$ of the variation in the number of reviews devoted to new fiction titles. As appears from the standardized regression coefficients in Table 9, 'reviewers' attention for previous work' bas a stronger effect on the amount of reviewers' attention for new fiction titles than both the other variables. In addition, the variable 'status of publishing house' proves to be of more significance than the 'size of the publishing house' that brought the title on the market.

\subsubsection{Analysis of reviewers' attention for first book publications}

This section examines the influence of the variables 'status and size of publishing house' upon the amount of attention first book publications receive from reviewers. Also the role of the variables 'genre', 'geographical origin' and 'generation' will be considered. 'First book publication' is understood to mean the author's debut as regards this particular genre. So, the first collection of poems by an author who already published one or more novels has been included in the corpus of analysis. As in the previous section, multiple regression analysis was applied and each of the independent variables was represented by a dummy variable. Genre is coded 1 for prose; 0 for poetry. Geographical origin is coded 1 for Dutch; 0 for Flemish.

Author's generation is coded 1 for authors born in 1935 or later; 0 for authors born before 1935. Status of publishing house is coded 1 for literary; 0 for non-literary. Size of publishing house is coded 1 for large; 0 for medium-sized or small.

Table 10

Multiple regression analysis of the number of reviews devoted to first book publications with five and three predictors, respectively

\begin{tabular}{lllll}
\hline Variable & \multicolumn{3}{c}{ Equation 1 } & \multicolumn{2}{c}{ Equation 2 } \\
\cline { 2 - 5 } & Beta & t-ratio & Beta & t-ratio \\
\hline Status of publishing house & 0.610 & $7.385^{* * *}$ & 0.609 & $5.194^{* * * *}$ \\
Size of publishing house & 0.238 & $3.033^{* *}$ & 0.238 & $3.071^{* *}$ \\
Genre & 0.152 & $2.284^{*}$ & 0.152 & $2.345^{*}$ \\
Geographical origin & -0.001 & -0.023 & & \\
Generation & -0.001 & -0.019 & & \\
& $R^{2}=0.62 * * *$ & $R^{2}=0.62^{* * *}$ & & \\
\hline
\end{tabular}

Note: $N=95 ; R^{2}=$ proportion of explained variance; Beta=standardized regression coefficient ${ }^{*} p<0.05 ; * \mathrm{p}<0.01 ; * * * \mathrm{p}<0.001$

First, it was tested if there was matter of interaction between the independent variables. Since this proved not to be the case, the analysis was continued with the testing of main effects. The results are given in Table 10.

The variables 'geographical origin' and 'generation' do not have a significant effect on the number of reviews devoted to first book publications. Each of the other variables contributes significantly to the explained variance. As can been seen from the right part of Table 10, these three variables account for more than $60 \%$ of the variance in the amount of critical attention for first book publications. However, the 
effect of 'status of publishing house' proves to be far more substantial than that of the other variables. In addition, the 'size of the publishing house' that brought the title on the market appears to be of more significance than the genre of the title.

\section{Concluding remarks}

The main task of reviewers is to assess the nature and value of newly published fiction titles. It is a common belief that in the fulfilment of this task, only intrinsic properties of the works under consideration should be taken into account. In contemporary criticism reviewers are supposed to ground their value judgements about literary texts by pointing to certain properties which they deem present in these texts. Due to the absence of clear and unequivocal criteria of judgement, this task is a highly uncertain affair. The characterization of a work that one reviewer adduces as an argument fora positive value judgement, may serve to justify another critic's negative judgement. Nevertheless, reviewers are presumed to assess a work's properties and value. We argued that this assessment affects the reputation of bath the works under discussion and the discussants themselves as literary experts. Therefore, reviewers tend to play safe when dealing with recently published texts. In addition to the text itself, they consider extra-textual indicators of quality such as the publishing house that marketed the title. Besides, reviewers take into account their colleagues' statements. In the final analysis these constitute the sole test for a reviewer's own statements, the only way he may be proved right or wrong. A critic's recognition as a connoisseur depends to a great extent on the similarity or comparability of his choices and statements to those made by his colleagues. In repeatedly taking a dissenting view, a critic risks his status of literary expert.

The research findings presented in this article provide empirical evidence on reviewing as social practice. Reviewers take due note of each other's achievements and adjust their choices and judgements to the ones made by other critics. There is a remarkable agreement and continuity in reviewers' selection of works for discussion. In bath years the attention of the reviewing community was found to be distributed very unequally over the stock of new titles. Critical attention appears to focus on a very limited number of works, indicating that reviewers agree as to which titles deserve their attention.

Furthermore, the analysis shows that the amount of reviewers' attention for a new title is highly predictable if the extent to which the critical community has paid attention to an author's previous work is taken into account. Reviewers seem aware of the prevailing literary hierarchy and inclined to reproduce previous critical choices and judgements. They show a preference for reviewing new titles by authors whose work has already been assessed by a substantial number of their colleagues. In doing so they reinforce the belief that the choices in question are legitimate ones.

Reviews of first book publications were found to be shorter than those regarding new works by authors who had published one or more hooks already. When discussing 
a book by a debutant, the reviewer is at greater risk of making statements which have to be reconsidered later on, because 'reliable' sources (for instance other reviews or interviews with the author) that a critic might use as a peg for formulating his response are lacking. This may be a reason why in most cases first book publications are discussed in rather brief terms.

The amount of critical attention for a first book publication was found to be highly predictable if the type of publishing house that marketed the title is taken into account. In so far as first book publications did receive a good deal of attention on the part of reviewers, these were almost exclusively books published by a large literary publishing house. The name of the publishing firm figuring on the blurb seems to serve as a quality indicator on the strength of which reviewers decide whether to pay attention to the title. In doing so, they reduce the uncertainty as to which first book publications deserve their attention, i.e. will be judged worthy of a review by their colleagues. Hence, by taking into account the publisher of the title, reviewers reduce the risk of making the wrong choices, that is choices that might jeopardize their status of literary expert. Once again a reproduction mechanism appears to be effective. After all, the name of a publishing house is inseparably connected with the reception of its publications within the critical community.

\section{References}

Alsem, KJ. et al., 1982. De aanbodstructuur van de periodiek verschijnende pers in Nederland [The supply of the press media in The Netherlands]. 's-Gravenshage: Staatsuitgeverij.

Becker, Howard S., 1982. Art worlds. Berkeley, CA: University of Califomia Press.

Bel, J., 1993. Nederlandse literatuur in het fin de siècle. Een receptie-historisch overzicht van het proza tussen 1885 en 1900 [Dutch fin de siècle literature. A reception-history research of Dutch prose between 1885 and 1900). Amsterdam: Amsterdam University Press.

Bevers, T., 1985. De chronische reflectie. Een sociologische beschouwing over beeldende kunst en kunstkritiek [The chronic reflection. A sociological view on art and art criticism). Sociologische Gids 32, 81-111.

Bourdieu, Pierre, 1980. The production of belief: Contribution to an economy of symbolic goods. Media, Culture and Society 2, 261-293.

Bourdieu, Pierre, 1983. The field of cultural production, or: The economic world reversed. Poetics 12, 311-356.

Dijk, Nel van, 1994. De politiek van de literatuurkritiek. De reputatie-opbouw van Menno ter Braak in de Nederlanse letteren [Pragmatic considerations in literary criticism. The establishment of the reputation of Menno ter Braak in Dutch literature]. Delft: Eburon.

Ellis, J.M., 1974. The theory of literary criticism. A logical analysis. Berkeley, CA: University of California Press.

Herpers, T., J. Hemels and H. Prins (eds.), 1993. Gids voor de informatiesector. Cijfers en trends [Guide for the information branch. Figures and trends]. 's-Gravenshage: Vuga/NBLC.

Janssen, Susanne, 1988. Institutional factors influencing the selection made by literary reviewers. SPIEL/Siegener Periodicum zur intemationalen empirischen Literaturwissenschaft 7(2), 281-291. Janssen,

Susanne, 1991. The modus operandi of literary reviewers. In: Elrud lbsch, Dick Schram and Gerard Steen (eds.), Empirical studies of literature, 185-194. Amsterdam/Atlanta: Rodopi.

Janssen, Susanne, 1994. In het licht van de kritiek. Variaties en patronen in de aandacht van de literatuurkritiek voor auteurs en werken [The spotlights of criticism. Divergences and patterns in the attention of literary criticism for authors and their works]. Hilversum: Verloren.

Janssen, Susanne (forthcoming). Literary sidelines and their effect on the reputation of writers.

Nationaal Onderzoek Persmedia [National Research Press Media], 1982. Amsterdam: Stichting Nationaal Onderzoek Persmedia. 
Nipo Media Onderzoek [Nipo Media Research], 1992.

Nooy, W. de, 1991. Social networks and classification in literature. Poetics 20(6), 507-537.

Pedhazur, Elazar J., 1982. Multiple regression in behavioral research. Explanation and prediction. New York: Holt, Rinehart and Winston.

Peterson, Richard A., 1985. Six constraints on the production of literary works. Poetics 14, 45- 67.

Radford, C. and S. Minogue, 1981. The nature of criticism. Sussex: Harvester Press.

Rees, C.J. van, 1983a. Advances in the empirical sociology of literature and the arts: The institutional approach. Poetics 12, 285-3JO.

Rees, C.J. van, 1983b. How a literary work becomes a masterpiece. On the threefold selection practiced by literary criticism. Poetics 12, 397-417.

Rees, C.J. van, 1986. Literary theory and criticism. Conceptions of literature and their application. Doctoral dissertation, University of Groningen.

Rees, C.J. van, 1987. How reviewers reach consensus on the value of literary works. Poetics 16, 275-294.

Rees, C.J. van, 1989. The institutional foundation of a critic's connoisseurship. Poetics 18, 179-198. Ritchie,

H., 1988. Success stories. Literature and the media in England, 1950-1959. London/Boston:

Faber and Faber.

Rodden, J., 1989. The polities of literary reputation. The making and claiming of 'St. George' Orwell. New York: Oxford University Press.

Rosengren, Karl E., 1985. Time and literary fame. Poetics 14, 157-172.

Rosengren, Karl E., 1987. Literary criticism: Future invented. Poetics 16, 295-326.

Schmidt, S.J., 1982. Die empirische Literaturwissenschaft ELW. Ein neues Paradigma. SPIEL/Siegener Periodicum zur intemationalen empirischen Literaturwissenschaft 1, 5-25.

Schmidt, S.J., 1989: Die Selbstorganisation des Sozialsystems Literatur im 18. Jahrhundert. Frankfurt am Main: Suhrkamp.

Verdaasdonk, H., 1981. Literatuurbeschouwing en argumentatie [Literary criticism and argumentation]. Amsterdam: Huis aan de Drie Grachten.

Verdaasdonk, H., 1983. Social and economie factors in the attribution of literary quality. Poetics 12, 383-395.

Verdaasdonk, H., 1987. Effects of acquired readership and reviewers' attention on the sales of new literary works. Poetics 16, 237-253.

Viehoff, Reinhold, 1989. Literaturkritik 1973 und 1988. Aspekte des literaturkritischen Wertwandels. Siegen: Lumis.

Viehoff, Reinhold, 1991. Conditions of the critical assessment of literature: Some theses and empirical data on the interplay of social contexts, actions, and values. In: Elrud lbsch, Gerard Steen and Dick Schram (eds.), Empirical studies of literature, 247-252. Amsterdam/Atlanta: Rodopi.

Weitz, M., 1966. Hamlet and the philosophy of literary criticism. Cleveland/New York: Meridian Books.

Willems, E.J. and H. Prins, 1977. Literaire recensies. Een kwantitatieve inhoudsanalyse [Literary reviews. A quantitative content analysis]. Amsterdam: Instituut voor Perswetenschap.

Zuiderent A, H. Brems and T. van Deel (eds.), 1980. Lexicon van de Nederlandstalige literatuur na 1945 [Lexicon of Dutch literature after 1945]. Alphen aan de Rijn: Samson. 